\title{
Novel X-Linked Inhibitor of Apoptosis Mutation in Very Early-Onset Inflammatory Bowel Disease Child Successfully Treated with HLA-Haploidentical Hemapoietic Stem Cells Transplant after Removal of $\alpha \beta^{+} \mathbf{T}$ and B Cells
}

OPEN ACCESS

Edited by:

Frédéric Rieux-Laucat, INSERM UMR1163 Institut Imagine, France

Reviewed by:

Silvia Clara Giliani,

University of Brescia, Italy Alessandra Magnani, Necker-Enfants Malades Hospital, France

*Correspondence: Andrea Finocch andrea.finocchi@uniroma2.it

Specialty section: This article was submitted to Primary Immunodeficiencies,

a section of the journal Frontiers in Immunology

Received: 07 July 2017 Accepted: 11 December 2017 Published: 22 December 2017

Citation: Cifaldi C, Chiriaco M, Di Matteo G, Di Cesare S, Alessia S, De Angelis P,

Rea $F$, Angelino G, Pastore $M$, Ferradini V, Pagliara D, Cancrini C, Rossi P, Bertaina A and Finocchi A (2017) Novel X-Linked Inhibitor of Apoptosis Mutation in Very

Early-Onset Inflammatory Bowel Disease Child Successfully Treated with HLA-Haploidentical Hemapoietic Stem Cells Transplant after Removal of $\alpha \beta^{+} T$ and $B$ Cells.

Front. Immunol. 8:1893. doi: 10.3389/fimmu.2017.01893
Cristina Cifaldi', Maria Chiriaco', Gigliola Di Matteo², Silvia Di Cesare', Scarselli Alessia², Paola De Angelis ${ }^{3}$, Francesca Rea ${ }^{3}$, Giulia Angelino' ${ }^{1}$, Maria Pastore ${ }^{4}$, Valentina Ferradini ${ }^{5}$, Daria Pagliara $^{6}$, Caterina Cancrini ${ }^{1,2}$, Paolo Rossi ${ }^{1,2}$, Alice Bertaina ${ }^{6}$ and Andrea Finocchi ${ }^{1,2 *}$

\begin{abstract}
'University Department of Pediatrics, Unit of Immunology and Infectious Diseases, Bambino Gesù Children's Hospital, Rome, Italy, ${ }^{2}$ Department of Systems Medicine, University of Rome Tor Vergata, Rome, Italy, ${ }^{3}$ Digestive Surgery and Endoscopy Unit, Bambino Gesù Children's Hospital, IRCCS, Rome, Italy, ${ }^{4}$ Division of Pediatrics, Casa Sollievo della Sofferenza Hospital, IRCCS, San Giovanni Rotondo, Foggia, Italy, ${ }^{5}$ Department of Biomedicine and Prevention, University Tor Vergata Rome, Rome, Italy, ${ }^{6}$ Department of Pediatric Hematology and Oncology, Bambino Gesù Children's Hospital, Rome, Italy
\end{abstract}

Monogenic defects in genes related to primary immunodeficiencies can be responsible for inflammatory bowel disease (IBD). Mutations in the X-linked inhibitor of apoptosis $(X I A P)$ gene have been described in several patients suffering from IBD and, in particular, with very early-onset inflammatory bowel disease (VEOIBD) features. We report a VEOIBD child with a novel XIAP gene mutation characterized by a complicated disease course, which is unresponsive to several medical treatment options. A nextgeneration sequencing was performed and revealed a de novo hemizygous mutation in XIAP gene: c.565T>C p.L189P. After mutation discovery, we investigated the XIAP protein expression and nucleotide-binding oligomerization domain protein 2 (NOD2) signaling by western blotting. Flow-cytometry was used to analyze intracellular protein expression in different cell subsets and T cell apoptosis. We observed reduced protein expression in lymphocytes, granulocytes, monocytes, an Epstein-Barr virus-immortalized B cell line as well as increased apoptosis, and impairment in NOD2 signaling. The child was successfully treated with HLA-haploidentical hemapoietic stem cells transplant, acquired from his mother, after ex vivo elimination of $\alpha / \beta$ T cells and CD19 B cells. One year after the transplant, we repeated the analysis to appreciate the changes in his impairments. The recovery of XIAP protein expression, function, and normalization of apoptosis were observed. Our report emphasizes the important role of genetic analysis in the diagnosis of VEOIBD, illustrates the complete immunological and gastrointestinal recovery after transplant, and shows one of the few successful transplant cases of XIAP patients.

Keywords: novel X-linked inhibitor of apoptosis mutation, very early-onset inflammatory bowel disease, immunodeficiency, hemapoietic stem cells transplant, immune and gastrointestinal recovery 


\section{HIGHLIGHTS}

- Very early-onset IBD patient

- Patient unresponsive to several medical treatment

- Next-generation sequencing reveals a new XIAP mutation

- The protein expression is reduced, but detectable

- Functional assays shows impaired NOD2 pathway

- XIAP protein expression and NOD2 pathway were compromised

- The HSCT led to a total immune and gastrointestinal healing

\section{INTRODUCTION}

Inflammatory bowel disease (IBD) is a heterogeneous group of chronic inflammatory disorders affecting the gastrointestinal (GI) tract, including Crohn's disease (CD) and ulcerative colitis. Both A chronic and relapsing inflammatory response against the intestinal microbiota is characteristic of both disorders.

The pathogenesis of IBD is complex and often associated with genetic predisposition, environmental factors, and/or epithelial barrier dysfunction, which cause persistent activation of the intestinal immune response (1-3). Primary immunodeficiencies (PIDs) may be the cause of the disease in a relevant portion of cases.

X-linked inhibitor of apoptosis (XIAP) inactivating mutations have been identified as cause for a rare $\mathrm{X}$-linked immune disorder 2 (XLP2), which similarly to X-linked immune disorder 1 (XLP1), is caused by mutation in $\mathrm{SH} 2$ domain protein $1 \mathrm{~A}$ gene. Classical XLP (XLP1) is characterized by susceptibility to Epstein-Barr virus (EBV) infection, frequently leading to hemophagocytic lymphohistiocytosis (HLH), with major clinical phenotypes including fulminant infectious mononucleosis, lymphoproliferative disorders, and dysgammaglobulinemia. By contrast, XLP2 is characterized by susceptibility to EBV and cytomegalovirus (CMV) infection, recurrent splenomegaly, chronic intestinal inflammation, risk of HLH, variable hypogammaglobulinemia, and auto-inflammatory manifestations. No case of lymphoma has been reported (4-15). XIAP mediates the signaling of

Abbreviations: PID, primaryimmunodeficiency; IBD, inflammatory bowel disease; $\mathrm{CD}$, Crohn's disease; UC, ulcerative colitis; VEOIBD, very early-onset inflammatory bowel disease; XLP1, X-linked immune disorder 1; XLP2, X-linked immune disorder 2; XIAP, X-linked inhibitor of apoptosis; NOD1, nucleotide-binding oligomerization domain protein 1; NOD2, nucleotide-binding oligomerization domain protein 2; SH2D1A, SH2 domain protein 1A; CMV, cytomegalovirus; EBV, Epstein-Barr virus; Hib, Haemophilus influenzae type b; IVIG, intravenous immunoglobulin treatment; ATLG, anti-T-lymphocyte globulin; GvHD, graftversus-host disease; GI, gastrointestinal; UGI, upper gastrointestinal endoscopy; HLH, hemophagocytic lymphohistiocytosis; TNF, tumor necrosis factor; HSCT, hemapoietic stem cells transplant; NGS, next-generation sequencing; PBMC, peripheral blood mononuclear cell; MDP, muramyl dipeptide; IL-1 $\beta$, interleukin 1 beta; IL-6, interleukin 6; IL-8, interleukin 8; IAP, inhibitor of apoptosis proteins; BIR, baculoviral IAP repeat homology domains; TAB1, TAK-binding protein 1; TAB2, TAK-binding protein 2; TAB3, TAK-binding protein 3; IKK, IкB kinase; MAP, mitogen activation protein; $\mathrm{I} \kappa \mathrm{B} \alpha$, inhibitor of kappa light chain gene enhancer in B cells, alpha; NF- $\kappa$ B, nuclear factor kappa B; LUBAC, linear ubiquitin chain assembly complex; SAP, slam-associated protein; TRM, transplant-related mortality; RIC, reduced-intensity conditioning; MAC, myeloablative conditioning. nucleotide-binding oligomerization domain nucleotide-binding oligomerization domain protein 1 (NOD1)/nucleotide-binding oligomerization domain protein 2 (NOD2) in response to bacterial pathogens and regulates tumor necrosis factor (TNF)mediated survival, inflammatory, and death-signaling pathways. XIAP is also a direct inhibitor of initiator and effector caspases.

In the last years, the proteins members of the inhibitor of apoptosis (IAP) family (cIAP1, cIAP2, and XIAP) with E3 ubiquitin ligase activity have been shown to mediate NOD2 signaling. Their mutations are commonly associated with IBD. XIAP is characterized by three baculoviral IAP repeat (BIR) homology domains, which are necessary to bind the TAK-binding protein 1 (TAB1), which, in turn, activates the nuclear factor light chain enhancer of activated B cells [nuclear factor kappa B (NF- $\mathrm{B})$ ] pathway, suppressing specific cell death-inducing caspases, such as caspase 3,9 , and 7, via its BIR2 and BIR3 domains $(3,16)$.

In this case report, we describe a patient with very early-onset inflammatory bowel disease (VEOIBD) who presented with EBV viremia and a complicated disease course, which was unresponsive to several lines of medical treatment options. The patient showed a novel and de novo hemizygous mutation in XIAP gene. Functional studies revealed a reduction of protein expression in an EBV-B cell line and in the lymphocytes, granulocytes, and monocytes subsets. The suspicion of a defective NOD2 pathway was demonstrated by the lack of $I \kappa B \alpha$ degradation and an increased activation-induced cell death in peripheral blood mononuclear cell (PBMC). The patient received haplo-hemapoietic stem cells transplant (HSCT) after negative depletion of $\mathrm{T} \alpha \beta^{+} / \mathrm{CD} 19^{+}$ lymphocytes with a complete immune-GI recovery.

\section{CASE REPORT}

We describe a 7-year-old first-born male patient from nonconsanguineous parents. The child was in good clinical health until 5 years of age, when, he presented with mucohemorrhagic diarrhea, fever, and abdominal pain, for which he was hospitalized with a suspicion of VEOIBD. Blood tests revealed anemia and elevation of inflammatory markers. The fecal calprotectin level was significantly increased.

While the upper gastrointestinal endoscopy was normal, the colonoscopy revealed diffuse colitis, without involvement of the small intestine. Standard antibiotic (ciprofloxacin and metronidazole) and steroid treatment (prednisone $1 \mathrm{mg} / \mathrm{kg}$ ) were administered with transitory clinical benefit, followed by relapse of mucohemorrhagic diarrhea during steroid taper.

Full endoscopic evaluation performed in our department revealed: intensely erythematous gastric mucosa with prepyloric erosions. The colonoscopy of the mucosa of the transverse colon, the left sigmoid colon, and the rectum appeared erythematous with ulcerations covered with fibrin. The biopsy indicated esophagitis, gastritis, and intestinal chronic inflammatory process with colonic histiocytic clusters (Figure 1A, top panels).

The child underwent an additional course of prednisone ( $2 \mathrm{mg} / \mathrm{kg}$ ) and began azathioprine (up to a dosage of $2.5 \mathrm{mg} / \mathrm{kg}$ ), for his apparent steroid dependence, with partial clinical benefit. At the same time, during episodes of fever and diarrhea, he received several treatments with metronidazole and/ 
A
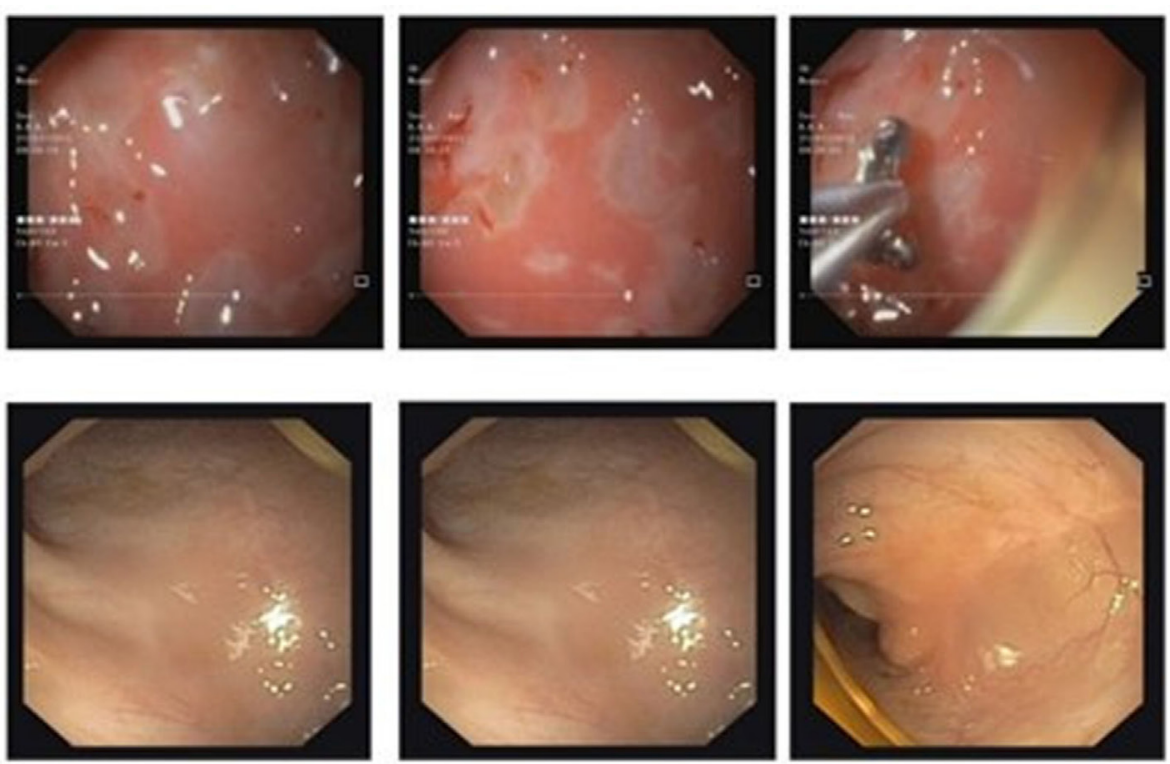

B

HD PT

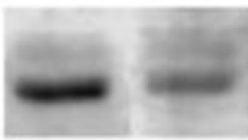

XIAP

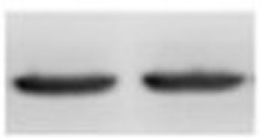

$\beta$-actin
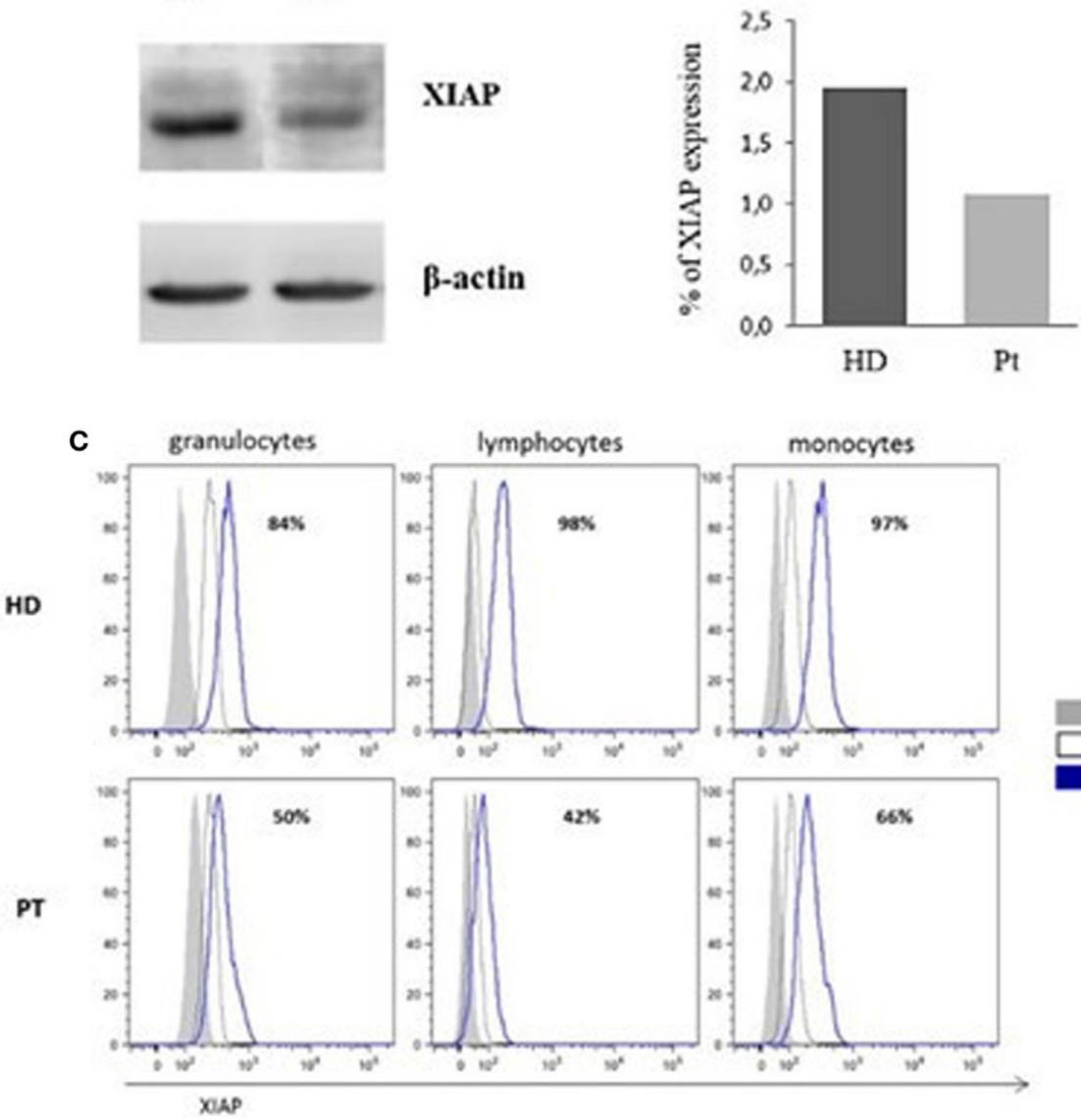

Xup stained unstained

isotype-mached Ab

FIGURE 1 | Image of colonoscopy investigation and X-linked inhibitor of apoptosis (XIAP) expression. (A) Colonoscopy features of the patient show the intensely erythematous mucosa, with prepyloric erosions, ulcerations covered with fibrin and intestinal chronic inflammatory process, with colonic histiocytic clusters (Top panels). Colonoscopy investigation 6 months after hemapoietic stem cells transplant revealed normal gastrointestinal and colonic mucosa with regular vascular patter (Bottom panels). (B) XIAP immunoblot in patient B-Epstein-Barr virus-cell line compared with healthy donor. Lysate were immunoblotted with anti-XIAP antibody and anti- $\beta$-actin as a loading control. Data are presented as percentage of protein expression. (C) Flow-cytometric histograms of XIAP expression. Assay was analyzed by means of intracellular staining lymphocytes, granulocytes, and monocytes in a healthy donor and XIAP patient. 
or ciprofloxacin, with a transient positive response, although all fecal cultures were negative.

Given the early onset of intestinal symptoms and the clinical severity, we performed a complete immunological investigation to exclude possible underlying primary immune defects. He had a mild decrease of IgG serum levels with poor antibody responses to tetanus toxoid, Haemophilus influenzae type b (Hib) and hepatitis B. Therefore, he was started on intravenous immunoglobulin treatment at a dose of $400 \mathrm{mg} / \mathrm{kg}$ every 3 weeks.

Of note, the patient showed persistent EBV viremia ranging from 1,218 to 32,466 copies/ml and absent seroconversion (no anti-EBNA production). A repeated colonoscopy confirmed severe pancolitis (macroscopic and microscopic findings) and PCR of DNA extracts from biopsies yielded a positive result for EBV DNA. Accordingly, the patient was administered rituximab; however, he did not tolerate therapy.

His disease course remained severe, complicated by infections, including adenovirus enteritis and pneumonia (with pleural effusion). The patient exhibited refusal of food and chronic malnutrition, despite support with polymeric formula and sometimes parenteral nutrition. Humira (80-40-20 mg) was administered twice per month for 4 months with no evidence of clinical remission.

In the meantime, next-generation sequencing (NGS) revealed a de novo and novel mutation in the XIAP gene: c.565T $>\mathrm{C}$ p.L189P, which, SIFT and Polyphen 2, predicted to be damaging and probably damaging, respectively. Sanger sequencing confirmed the mutation in the patient and his parents (on DNA extracted both from peripheral blood and from mouth rinsing to assess the germline mutations); however, the substitution was found only in the patient.

Since the L189P is located in the BIR2 domain of XIAP, to establish if BIR2 mutation impairs protein expression, PBMCs isolated from the patient were cultured and transformed into an EBV-immortalized B-cell line, then immunoblotted for XIAP. Reduced protein expression was observed in cells from the patient compared with a healthy control (Figure 1B).

Afterward, we investigated the XIAP expression in different cell subsets. In accordance with our result, intracellular XIAP expression was markedly reduced in lymphocytes, granulocytes, and monocytes (Figure 1C). Typically, the NOD2 activation and the XIAP/RIPK2 recruitment lead to the NF- $\kappa B$ translocation to the nucleus after I $\mathrm{B} \alpha$ degradation. To determine the effect of this mutation on NOD2 pathway, we investigated the XIAP direct-binding protein, RIPK2, which did not reveal alterations (Figure 2A). In addition, we studied the $\mathrm{I} \kappa \mathrm{B} \alpha$ degradation in patient's EBV-immortalized B-cell line stimulated with muramyl dipeptide (MDP), a specific NOD2-activating ligand. Consistent with the data, after stimulation, I $\kappa \mathrm{B} \alpha$ degradation was absent, suggesting defective NF- $\kappa$ B activation (Figure $2 B$ ).

Since XIAP is a potent and direct caspase inhibitor and an antiapoptotic protein, we decided to investigate whether the patient's mutation affects this function. We performed an in vitro apoptosis assay in $\mathrm{CD}^{+}$and $\mathrm{CD} 8^{+} \mathrm{T}$ cells from the patient's $\mathrm{PBMC}$ stimulated with OKT3/CD28 or MDP for $24 \mathrm{~h}$. MDP-stimulated $\mathrm{CD}^{+}$and $\mathrm{CD}^{+} \mathrm{T}$ cells had the same features of OKT3/CD28 stimulated T cells, with further propensity to apoptosis compared with a healthy control. Interestingly, analysis of the patient's cells revealed an increased level of basal apoptosis without stimulation (Figures 2C,D). Our patient exhibited increased activationinduced cell death, which may reflect the alteration of NOD2 signaling and the inability of the XIAP protein to inhibit the caspases.

Considering the unresponsiveness to several different lines of therapy, and since the patient did not have any suitable related or fully allelic-matched unrelated donor, we decided to perform HLA-haploidentical HSCT (haplo-HSCT) after negative depletion of $\mathrm{T} \alpha \beta^{+} / \mathrm{CD} 19^{+}$lymphocytes, using the mother as donor. This type of allograft permits $\mathrm{CD} 34^{+}$cells, committed hematopoietic progenitor cells, fully functioning donor $\mathrm{NK}$ and $\gamma \delta^{+} \mathrm{T}$ cells to remain in the graft. Recent studies have shown that $\mathrm{T} \alpha \beta^{+} / \mathrm{CD} 19^{+}$ cell depleted haplo-HSCT is a suitable option for the definitive treatment of a wide spectrum of malignant and non-malignant disorders, in the absence of an HLA-identical donor. This technique allows a rapid engraftment, low graft failure rate, and low incidence of significant aGvHD $(17,18)$. The child was included in clinical trial protocol (NCT02065869), which was approved by the ethical committee of Bambino Gesù Children's Hospital. This treatment regimen consisted of myeloablative [myeloablative conditioning (MAC)], but reduced-toxicity conditioning, including the combination of thiotepa $(8 \mathrm{mg} / \mathrm{kg})$, treosulfan $\left(42 \mathrm{~g} / \mathrm{m}^{2}\right.$ over 3 days), fludarabine $\left(160 \mathrm{mg} / \mathrm{m}^{2}\right.$ over 4 days), and antiT-lymphocyte globulin (ATLG, Grafalon, Neovii) to prevent graftversus-host disease (GvHD) and graft failure. One single dose of rituximab (200 mg/mq) on day -1 was employed for preventing EBV-related posttransplant lymphoproliferative disorder. The patients did not receive any post-HSCT pharmacological GvHD prophylaxis. The median time to reach neutrophil and platelet engraftment was 13 and 11 days, respectively, and he achieved a full donor chimerism. No toxicities or serious adverse events occurred.

Endoscopic evaluation 3 and 6 months after HSCT showed normal upper GI mucosa, normal colonic mucosa with regular vascular patter, a cecal pseudo-polyp (histology: no signs of GvHD, mild esophagitis, and signs of previous colonic inflammation with regeneration) (Figure 1A, bottom panels). At present time, the child is 1-year post-HSCT and is in very good general condition with full donor chimerism.

One year after transplant, we analyzed again the expression of XIAP by intracellular staining and western blotting (Figures 3A,B) again. The protein expression was restored in all leukocyte subsets and the EBV-B-cell line. Moreover, IкB $\alpha$ degradation was detected, suggesting a reinstated $\mathrm{NF}-\kappa \mathrm{B}$ activation (Figure 3C). See Figure 3 legend. Finally, 6 months and 1 year following HSCT, we performed the apoptosis assay to evaluate the antiapoptotic capacity, which was comparable to healthy donor (Figure 3D).

\section{DISCUSSION}

Inflammatory bowel disease has been identified as a possible sign of several recently discovered PIDs; it may be a clinical feature of a multisystemic disease or a consequence of epithelial barrier defects, phagocytic defects, $\mathrm{B}$ and $\mathrm{T}$ cell abnormalities (severe 

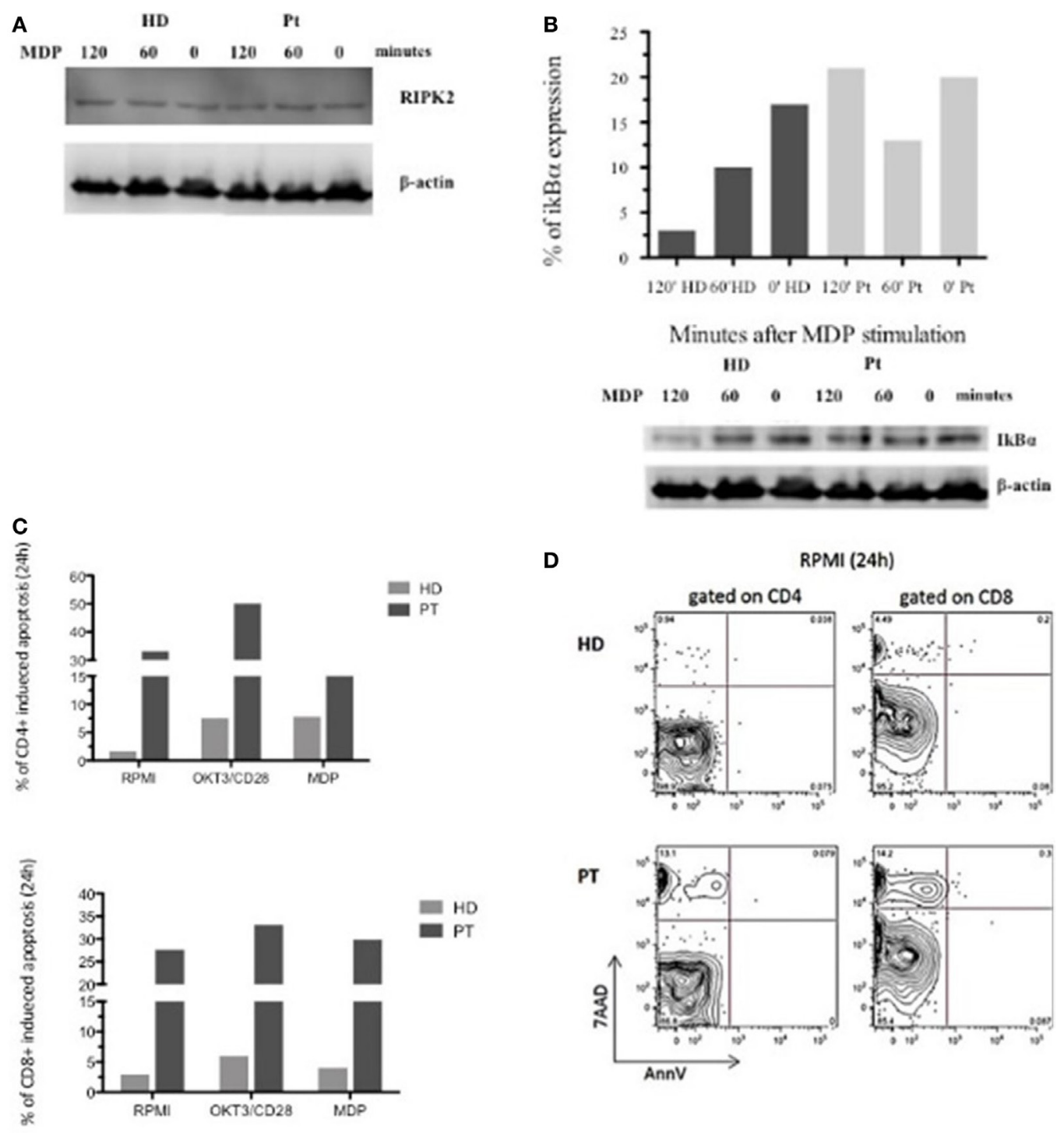

FIGURE 2 | Defective nuclear factor kappa B activation in X-linked inhibitor of apoptosis-deficient patient in response to nucleotide-binding oligomerization domain protein 2 stimulation and flow-cytometric cell-death assay. (A,B) RIPK2 expression and impaired lкB $\alpha$ degradation in patient and healthy donor Epstein-Barr virus-B-cell line. Lysate were analyzed for anti-IкB $\alpha$, anti-RIPK2, and loading control anti- $\beta$-actin. (C) In vitro apoptosis assay in CD4+ and CD8 ${ }^{+} \mathrm{T}$ cells from patient's peripheral blood mononuclear cell stimulated with OKT3/CD28 or muramyl dipeptide (MDP) for $24 \mathrm{~h}$. Histograms represent the mean of three independent experiments. (D) T cell gated on $\mathrm{CD}^{+}$and $\mathrm{CD} 8^{+}$unstimulated stimulated for $24 \mathrm{~h}$ and analyzed by $7 \mathrm{AAD}$ expression and Annexin $\mathrm{V}$.

combined immunodeficiency, common variable immunodeficiency, Wiskott-Aldrich syndrome), autoimmunity (XLP2), and IL10R defects (19-21).

$\mathrm{X}$-linked inhibitor of apoptosis has an important role downstream of the NOD1 and NOD2 immune receptors (22-24) and as previously reported, mutations in NOD2 are a predisposition to the development of $\mathrm{CD}(1,25)$. These receptors are expressed primarily in monocytes and induce activation of mitogen activation protein kinases and NF- $\mathrm{KB}$, leading to production of proinflammatory cytokines, such as TNF, interleukin (IL)-1 $\beta$, IL-6, and IL-8, and various antimicrobial peptides $(26,27)$. Monocytes from patients with XIAP deficiency have an impaired ability to secrete cytokines in response to stimulation by NOD2 ligands.
Upon binding of MDP to the NOD2-receptor, the receptorinteracting protein 2 (RIP2) is recruited with IAPs proteins. This complex ubiquitinates RIP2, which acts as a scaffold for TAK1 and TAK-binding protein 2/TAK-binding protein 3 together with I $\mathrm{B}$ kinase and linear ubiquitin chain assembly complex. As a result, $\mathrm{I} \kappa \mathrm{B} \alpha$ is phosphorylated and targeted for degradation, releasing $\mathrm{NF}-\kappa \mathrm{B}(3,28-30)$.

Interestingly, a study by Damgaard et al., which analyzed the function of XIAP mutations from XLP2 individuals, revealed that they have defective NOD2 signaling. This may explain the association of IBD with XLP2 $(3,6)$.

$\mathrm{X}$-linked inhibitor of apoptosis protein, as an antiapoptotic molecule, consists of 497 amino acids containing three baculovirus 
A

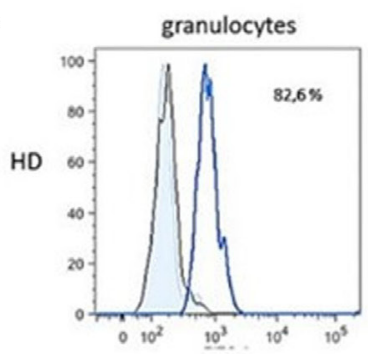

Pt

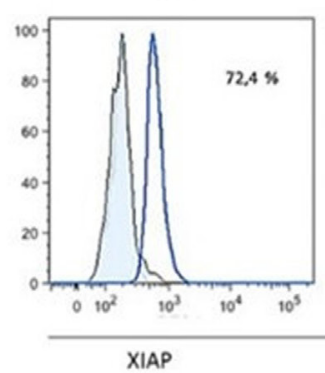

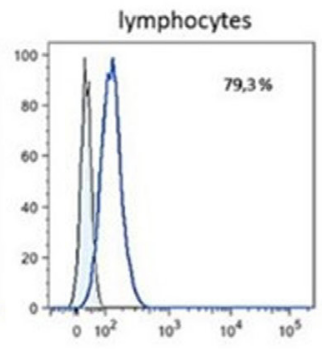
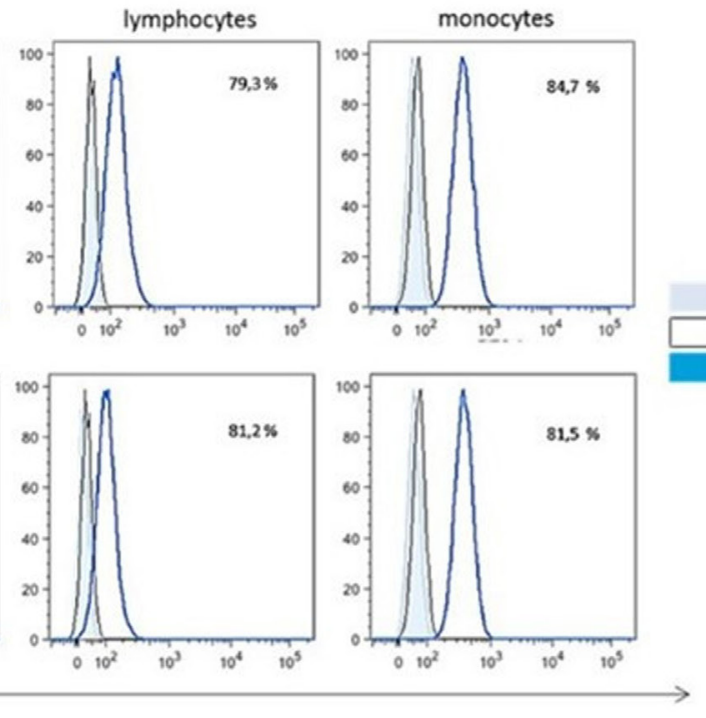

C

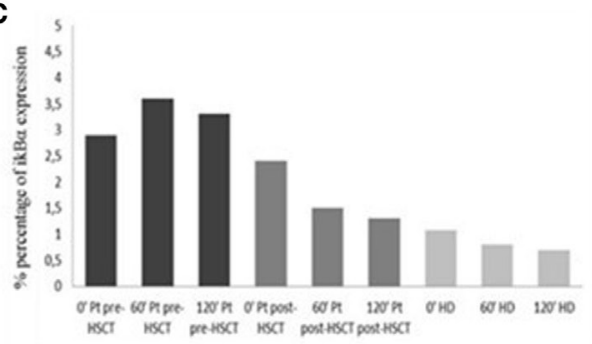

B
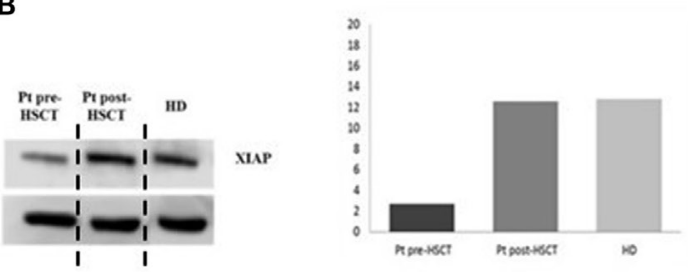

Minutes after MDP stimulation

D

RPMI
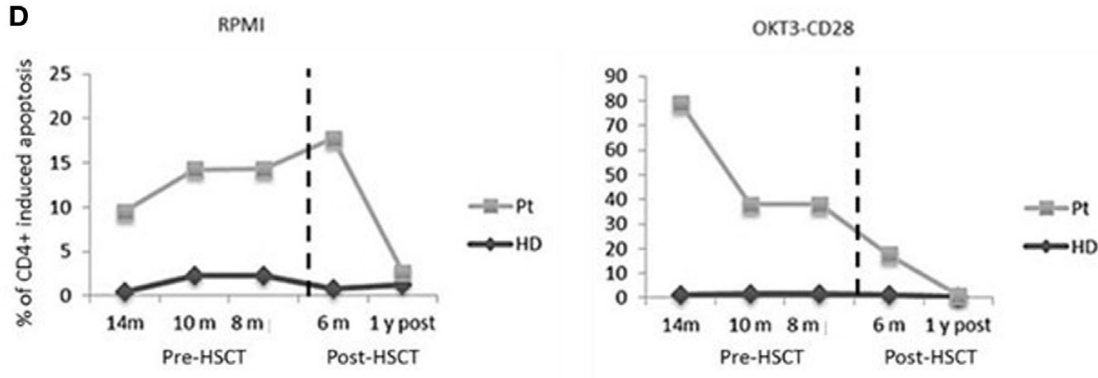

MDP

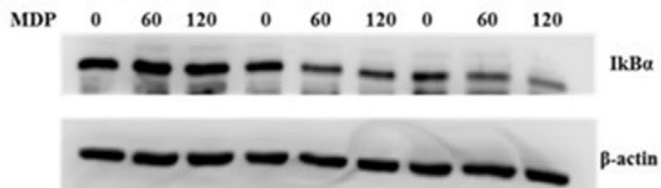

isotype-mached $A B$

XIAP stained
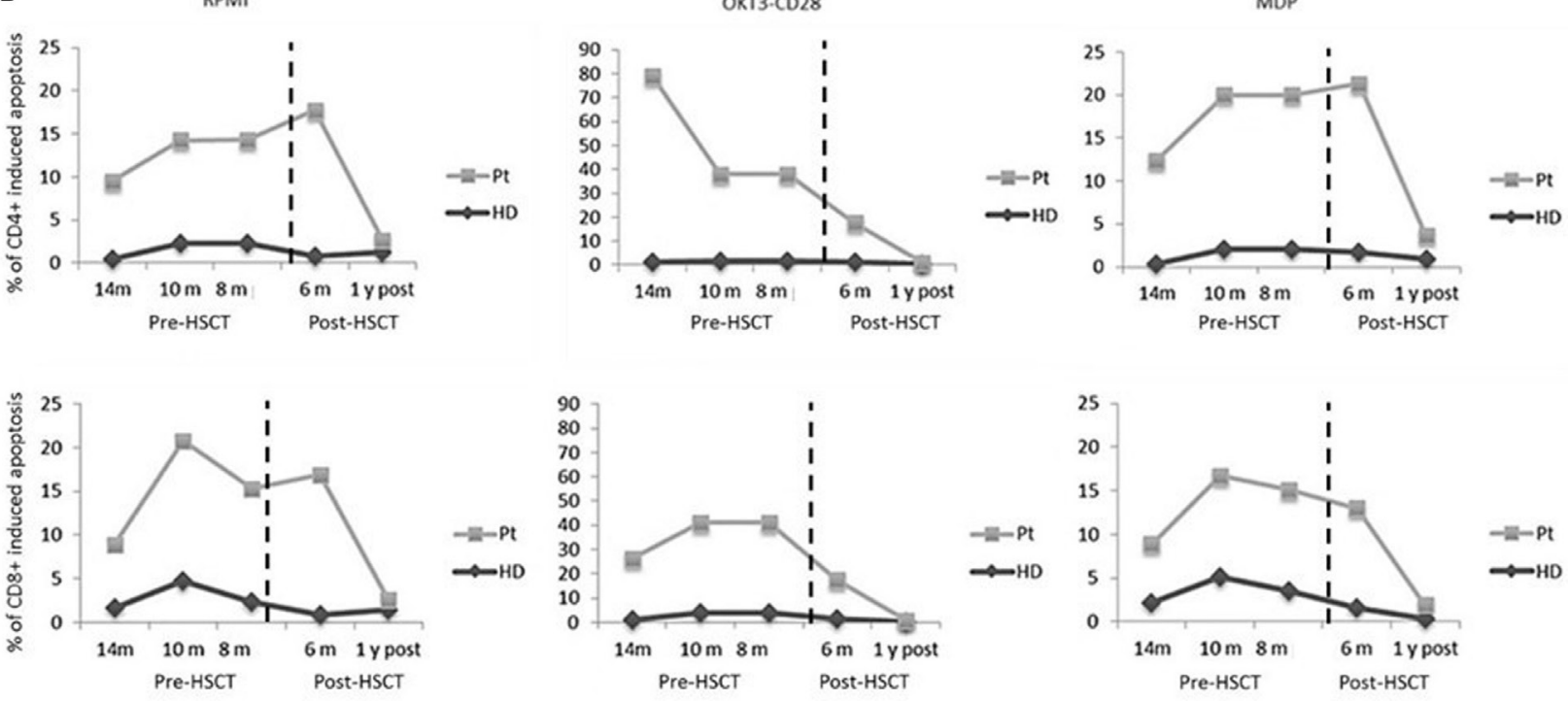

FIGURE 3 | Continued 
FIGURE 3 |X-linked inhibitor of apoptosis (XIAP) expression. (A) Flow-cytometric XIAP expression 1-year post-hemapoietic stem cells transplant (HSCT). (B) Reestablished XIAP immunoblot in patient B-Epstein-Barr virus-cell line compared with healthy donor. The XIAP expression has been derived from the same $I_{\kappa} B \alpha$ immunoblot $(\mathbf{C})$ incubated with anti-XIAP. The only time point 0 is showed. Data are presented as percentage of protein expression. Dashed vertical lines separate the time point 0 showed in panel (B) for XIAP immunoblot. (C) Restored IкB $\alpha$ degradation in response to nucleotide-binding oligomerization domain protein 2 stimulation. (D) Time course of pre/post-HSCT cell-death assay. T cell gated on CD4+ and CD8+ unstimulated, OKT3/CD28, or muramyl dipeptide (MDP) stimulated for $24 \mathrm{~h}$ and analyzed by $7 \mathrm{AAD}$ expression.

IAP repeat domains (BIR1, BIR2, and BIR3) and one RING and UBA domain, respectively. These BIR domains allow the binding of XIAP to caspases 3, 7, and 9 inhibiting the proteolytic activity of caspases 3, 7, and 9 (31). The increased apoptosis basally and after stimulation, seen in our patient, likely reflects the impaired function of the BIR2 domain to bind and inhibit caspases. Moreover, we could hypothesize that the L189P mutation prevents the binding of XIAP with RIP2 protein altering the downstream signal transduction and the activation of NF- $\mathrm{B}$, as seen in the patient.

Most of XIAP mutations described in XLP2 (such as nonsense and frameshift mutations or deletions) fall throughout the protein length leading to severe aberrations in the encoded protein and loss of expression. On the contrary, missense mutations cluster in two hotspots, the BIR2 and RING domains exactly like how L189P mutation (6).

Recent observations reveal that IBD due to XIAP defect is most commonly a pediatric disease presenting in the first years of life. Pediatric patients often present with more severe symptoms and a more aggressive disease course than is observed in adult patients. This disease negatively affects the quality of life of young patients in which the impact of the disease on growth and nutrition necessitates careful management to ensure physical and psychosocial functioning (12). While there are no significant immunologic abnormalities, the clinical manifestations including HLH, recurrent splenomegaly, and IBD are severe. These patients are susceptible to EBV and CMV infection, which could be explained by defects in adaptive immunity affecting T-lymphocyte responses-a critical immune response to viral infections (11). As described earlier, our patient showed mild humoral abnormality and persistent EBV viremia without evidence of HLH. Despite the absence of major immunological features, several defects associated with XIAP deficiency have been demonstrated in vitro (11). Our data demonstrate the compromised XIAP protein expression and function in the NOD2 signaling. This process may cause an altered production of proinflammatory cytokines as well as the autophagic elimination of intracellular bacteria. IBD is generally severe and drug-resistant with a fatal outcome in the lesser part of the cases, with the only possible curative treatment being HSCT. Nevertheless, HSCT in XIAP patients has been associated initially with bad prognosis compared with slam-associated protein deficiency and there are a limited number of studies concerning the outcomes of HSCT in patients with XIAP deficiency (32-39). While HSCT may be supported for patients with inherited immunodeficiencies that cause HLH (due to the life-threatening nature of HLH), the complicated course of some patients warrants precaution with this procedure $(32,33)$. In terms of allo-HSCT for XIAP deficiency, Marsh et al. described the international experience in 19 patients showing an extremely high transplant-related mortality in those prepared with an MAC (7/8 patients died), in comparison with those receiving a reduced-intensity conditioning (RIC) (5/11 patients died) (32). Thus, in this setting, the use of MAC has been associated with significantly higher mortality. It is possible that the loss of XIAP and its antiapoptotic functions contributes to the high incidence of treatment-related toxicities observed with MAC regimens (16). Indeed, patients transplanted with MAC regimens have a survival of approximately $60 \%$ and a risk of death for toxicities and complications including pulmonary hemorrhage, pulmonary hypertension, GvHD, sepsis, and multiorgan failure. However, one case of a patient who received MAC HSCT with a good follow-up and free of disease is reported (35). On the contrary, patients who received RIC had a survival rate of approximately $80 \%$ (35-37). Overall, the choice of HSCT for XIAP deficiency reveals poor outcomes and there is a propensity toward an RIC regime. The absence of HLH, in our patient, was likely responsible for the success of the transplant. The presence of HLH is an important factor in the choice of conditioning. The goal of transplantation in patients with XIAP deficiency is to establish sufficient donor cell engraftment to prevent HLH recurrence; however, there is no consensus regarding the lowest level of donor chimerism required to prevent disease relapse following HSCT. It is prudent to closely monitor chimerism in these patients' posttransplant period, due to an increased risk of mixed chimerism. This is consistent with earlier findings suggesting that whole blood donor chimerism greater than $20 \%$ appears to be sufficient to protect against HLH recurrence $(35,38)$.

\section{CONCLUDING REMARKS}

We herein described a child with VEOIBD with a novel XIAP mutation, who received a TCR $\alpha \beta^{+} \mathrm{T}$ cell- and $\mathrm{CD} 19^{+} \mathrm{B}$ celldepleted haploidentical HSCT from his maternal donor. During the short follow-up period, a complete immune and GI recovery was observed, although a long-term follow-up is required to confirm the reconstitution. Genetic testing, in particular for atypical presentations, and early diagnosis are fundamental to prevent the worsening of XIAP disease. Therefore, XIAP should be suspected for those forms of early onset of IBD in which a prompt diagnosis may allow an appropriate treatment (i.e., HSCT) for the purpose of optimal management of the patient.

\section{ETHICS STATEMENT}

All procedures performed in the study were in accordance with the ethical standards of the institutional research committee and with the 1964 Helsinki declaration and its later amendments or comparable ethical standards. Informed consent was obtained 
from the patient and was approved by the Institutional Ethical Committee of Ospedale Pediatrico Bambino Gesù and signed by his parents.

\section{AUTHOR CONTRIBUTIONS}

CC designed and performed experiments, analyzed the data, and wrote the paper; MC, GM, and SC performed laboratory analysis and contributed to data collection, interpretation, and revision of the manuscript; VF, GM, and CC performed the NGS and the bioinformatic analyses; SA, PA, FR, GA, MP, DP, CC, PR, AB, and $\mathrm{AF}$ have been important part in complicated diagnostic and therapeutic course and give valuable interpretation of data. AF supervised the project. All the coauthors revised paper critically and gave final approval of this version for publishing.

\section{REFERENCES}

1. Jostin L, Ripke S, Weersma RK, Duerr RH, McGovern DP, Hui KY, et al. Hostmicrobe interactions have shaped the genetic architecture of inflammatory bowel disease. Nature (2012) 491(7422):119-24. doi:10.1038/nature11582

2. Mokry M, MiddendorpS, Wiegerinck CL, Witte M, Teunissen H, Meddens CA, et al. Many inflammatory bowel disease risk loci include regions that regulate gene expression in immune cells and the intestinal epithelium. Gastroenterology (2014) 146(4):1040-7. doi:10.1053/j.gastro.2013.12.003

3. Pedersen J, LaCasse EC, Seidelin JB, Coskun M, Nielsen OH. Inhibitors of apoptosis (IAPs) regulate intestinal immunity and inflammatory bowel disease (IBD) inflammation. Trends Mol Med (2014) 20(11):652-65. doi:10.1016/j. molmed.2014.09.006

4. Rigaud S, Fondanèche MC, Lambert N, Pasquier B, Mateo V, Soulas P, et al. XIAP deficiency in humans causes an X-linked lymphoproliferative syndrome. Nature (2006) 444(7115):110-4. doi:10.1038/nature05257

5. Aguilar C, Lenoir C, Lambert N, Bègue B, Brousse N, Canioni D, et al. Characterization of Crohn disease in X-linked inhibitor of apoptosis-deficient male patients and female symptomatic carriers. J Allergy Clin Immunol (2014) 134(5):1131-41.e9. doi:10.1016/j.jaci.2014.04.031

6. Damgaard RB, Fiil BK, Speckmann C, Yabal M, zur Stadt U, Bekker-Jensen S, et al. Disease-causing mutations in the XIAP BIR2 domain impair NOD2dependent immune signalling. EMBO Mol Med (2013) 5(8):1278-95. doi:10.1002/emmm.201303090

7. Filipovich AH, Zhang K, Snow AL, Marsh RA. X-linked lymphoproliferative syndromes: brothers or distant cousins? Blood (2010) 116(18):3398-408. doi:10.1182/blood-2010-03-275909

8. Marsh RA, Madden L, Kitchen BJ, Mody R, McClimon B, Jordan MB, et al. XIAP deficiency: a unique primary immunodeficiency best classified as $\mathrm{X}$-linked familial hemophagocytic lymphohistiocytosis and not as X-linked lymphoproliferative disease. Blood (2010) 116(7):1079-82. doi:10.1182/ blood-2010-01-256099

9. Pachlopnik Schmid J, Canioni D, Moshous D, Touzot F, Mahlaoui N, Hauck F, et al. Clinical similarities and differences of patients with X-linked lymphoproliferative syndrome type 1 (XLP-1/SAP deficiency) versus type 2 (XLP-2/XIAP deficiency). Blood (2011) 117(5):1522-9. doi:10.1182/blood-2010-07-298372

10. Yang X, Kanegane H, Nishida N, Imamura T, Hamamoto K, Miyashita R, et al. Clinical and genetic characteristics of XIAP deficiency in Japan. J Clin Immunol (2012) 32(3):411-20. doi:10.1007/s10875-011-9638-z

11. Latour S, Aguilar C. XIAP deficiency in humans. Semin Cell Dev Biol (2015) 39:115-23. doi:10.1016/j.semcdb.2015.01.015

12. Mamula P, Markowitz JE, Baldassano RN. Inflammatory bowel disease in early childhood and adolescence: special considerations. Gastroenterol Clin North Am (2003) 32(3):967-95,viii. doi:10.1016/S0889-8553(03)00046-3

13. Sumegi J, Huang D, Lanyi A, Davis JD, Seemayer TA, Maeda A, et al. Correlation of mutations of the SH2D1A gene and EpsteinBarr virus infection with clinical phenotype and outcome in Xlinked lymphoproliferative disease. Blood (2000) 96:3118-25.

\section{ACKNOWLEDGMENTS}

The authors thank the Dr. M. Malamisura, Dr. S. Faraci, and Ospedale Pediatrico Bambino Gesù staff for their contribution to this study, the patient and his family.

\section{FUNDING}

This work was supported by the European CommissionAdvanced Cell-based Therapies for the treatment of Primary Immuno-Deficiency (HEALTH-F5-2010-261387, CELL-PID) Italian Ministero della Salute (NET-2015-01X003642), Telethon (201545X003661), and Ospedale Pediatrico Bambino Gesù Ricerca Corrente (201602P003708).

14. Seemayer TA, Gross TG, Egeler RM, Pirruccello SJ, Davis JR, Kelly CM, et al $\mathrm{X}$-linked lymphoproliferative disease: twenty-five years after the discovery. Pediatr Res (1995) 38:471-8. doi:10.1203/00006450-199510000-00001

15. Tangye SG. XLP: clinical features and molecular etiology due to mutations in SH2D1A encoding SAP. J Clin Immunol (2014) 34:772-9. doi:10.1007/ s10875-014-0083-7

16. Jost PJ, Grabow S, Gray D, McKenzie MD, Nachbur U, Huang DC, et al. XIAP discriminates between type I and type II FAS-induced apoptosis. Nature (2009) 460:1035-9. doi:10.1038/nature08229

17. Bertaina A, Merli P, Rutella S, Pagliara D, Bernardo ME, Masetti R, et al. HLA-haploidentical stem cell transplantation after removal of $\alpha \beta+\mathrm{T}$ and B cells in children with nonmalignant disorders. Blood (2014) 124(5):822-6. doi:10.1182/blood-2014-03-563817

18. Shah RM, Elfeky R, Nademi Z, Qasim W, Amrolia P, Chiesa R, et al. TCR $\alpha \beta^{+}$ and $\mathrm{CD} 19^{+}$cell-depleted haploidentical and mismatched hematopoietic stem cell transplantation in primary immune deficiency. J Allergy Clin Immunol (2017) S0091-6749(17):31202-2. doi:10.1016/j.jaci.2017.07.008

19. Glocker EO, Kotlarz D, Boztug K, Gertz EM, Schäffer AA, Noyan F, et al. Inflammatory bowel disease and mutations affecting the interleukin-10 receptor. N Engl J Med (2009) 361:2033-45. doi:10.1056/NEJMoa0907206

20. Glocker EO, Frede N, Perro M, Sebire N, Elawad M, Shah N, et al. Infant colitis it's in the genes. Lancet (2010) 376:1272. doi:10.1016/S0140-6736(10)61008-2

21. Moran CJ, Walters TD, Guo CH, Kugathasan S, Klein C, Turner D, et al. IL-10R polymorphisms are associated with very-early-onset ulcerative colitis. Inflamm Bowel Dis (2013) 19(1):115-23. doi:10.1002/ibd.22974

22. Girardin SE, Boneca IG, Viala J, Chamaillard M, Labigne A, Thomas G, et al. Nod2 is a general sensor of peptidoglycan through muramyl dipeptide (MDP) detection. J Biol Chem (2003) 278:8869-72. doi:10.1074/jbc.C200651200

23. Inohara N, Ogura Y, Fontalba A, Gutierrez O, Pons F, Crespo J, et al. Host recognition of bacterial muramyl dipeptide mediated through NOD2. Implications for Crohn's disease. J Biol Chem (2003) 278:5509-12. doi:10.1074/ jbc.C200673200

24. Van Limbergen J, Wilson DC, Satsangi J. The genetics of Crohn's disease. Annu Rev Genomics Hum Genet (2009) 10:89-116. doi:10.1146/ annurev-genom-082908-150013

25. Hugot JP, Chamaillard M, Zouali H, Lesage S, Cezard JP, Belaiche J, et al. Association of NOD2 leucine-rich repeat variants with susceptibility to Crohn's disease. Nature (2001) 411:599-603. doi:10.1038/35079107

26. Ogura $\mathrm{Y}$, Inohara $\mathrm{N}$, Benito A, Chen FF, Yamaoka S, Nunez G. Nod2, a Nod1/Apaf-1 family member that is restricted to monocytes and activates NF-kappaB. J Biol Chem (2001) 276:4812-8. doi:10.1074/jbc.M008072200

27. Ammann S, Elling R, Gyrd-Hansen M, Dückers G, Bredius R, Burns SO, et al. A new functional assay for the diagnosis of X-linked inhibitor of apoptosis (XIAP) deficiency. Clin Exp Immunol (2014) 176(3):394-400. doi:10.1111/ cei.12306

28. Strober W, Murray PJ, Kitani A, Watanabe T. Signalling pathways and molecular interactions of NOD1 and NOD2. Nat Rev Immunol (2006) 6(1):9-20. doi: $10.1038 /$ nri1747 
29. Krieg A, Correa RG, Garrison JB, Le Negrate G, Welsh K, Huang Z, et al. XIAP mediates NOD signaling via interaction with RIP2. Proc Natl Acad Sci U S A (2009) 106(34):14524-9. doi:10.1073/pnas.0907131106

30. Damgaard RB, Nachbur U, Yabal M, Wong WW, Fiil BK, Kastirr M, et al. The ubiquitin ligase XIAP recruits LUBAC for NOD2 signaling in inflammation and innate immunity. Mol Cell (2012) 46(6):746-58. doi:10.1016/j. molcel.2012.04.014

31. Galbán S, Duckett CS. XIAP as a ubiquitin ligase in cellular signaling. Cell Death Differ (2010) 17:54-60. doi:10.1038/cdd.2009.81

32. Marsh RA, Rao K, Satwani P, Lehmberg K, Müller I, Li D, et al. Allogeneic hematopoietic cell transplantation for XIAP deficiency: an international survey reveals poor outcomes. Blood (2013) 121(6):877-83. doi:10.1182/ blood-2012-06-432500

33. Marsh RA, BleedsingJJ, Chandrakasan S, Jordan MB, Davies SM, Filipovich AH. Reduced-intensity conditioning hemapoietic cell transplantation is an effective treatment for patients with SLAM-associated protein deficiency/X-linked lymphoproliferative disease type I. Biol Blood Marrow Trasplant (2014) 20:1641-5. doi:10.1016/j.bbmt.2014.06.003

34. Jiang MY, Guo X, Sun SW, Li Q, Zhu YP. Successful allogeneic hematopoietic stem cell transplantation in a boy with X-linked inhibitor of apoptosis deficiency presenting with hemophagocytic lymphohistiocytosis: a case report. Exp Ther Med (2016) 12(3):1341-4. doi:10.3892/etm.2016.3498

35. Chellapandian D, Krueger J, Schechter T, Gassas A, Weitzman S, Naqvi A, et al. Successful allogeneic hematopoietic stem cell transplantation in XIAP deficiency using reduced-intensity conditioning. Pediatr Blood Cancer (2016) 63(2):355-7. doi:10.1002/pbc.25756

36. Tsuma Y, Imamura T, Ichise E, Sakamoto K, Ouchi K, Osone S, et al. Successful treatment of idiopathic colitis related to XIAP deficiency with allo-HSCT using reduced-intensity conditioning. Pediatr Transplant (2015) 19(1):E25-8. doi:10.1111/petr. 12405

37. Worth AJ, Nikolajeva O, Chiesa R, Rao K, Veys P, Amrolia PJ. Successful stem cell transplant with antibody-based conditioning for XIAP deficiency with refractory hemophagocytic lymphohistiocytosis. Blood (2013) 121:4966-8. doi:10.1182/blood-2013-01-478735

38. Marsh RA, Vaughn G, Kim MO, Li D, Jodele S, Joshi S, et al. Reduced-intensity conditioning significantly improves survival of patients with hemophagocytic lymphohistiocytosis undergoing allogeneic hematopoietic cell transplantation. Blood (2010) 116:5824-31. doi:10.1182/blood-2010-04-282392

39. Ono S, Okano T, Hoshino A, Yanagimachi M, Hamamoto K, Nakazawa Y, et al. Hematopoietic stem cell transplantation for XIAP deficiency in Japan. J Clin Immunol (2017) 37(1):85-91. doi:10.1007/s10875-016-0348-4

Conflict of Interest Statement: All authors declare that the research was conducted in the absence of any commercial or financial relationships that could be construed as a potential conflict of interest.

Copyright (C) 2017 Cifaldi, Chiriaco, Di Matteo, Di Cesare, Alessia, De Angelis, Rea, Angelino, Pastore, Ferradini, Pagliara, Cancrini, Rossi, Bertaina and Finocchi. This is an open-access article distributed under the terms of the Creative Commons Attribution License (CC BY). The use, distribution or reproduction in other forums is permitted, provided the original author(s) or licensor are credited and that the original publication in this journal is cited, in accordance with accepted academic practice. No use, distribution or reproduction is permitted which does not comply with these terms. 